02

\title{
Исследование структурного совершенства монокристаллов ниобата лития разного состава и генезиса методом ИК спектроскопии в области валентных колебаний водородных связей
}

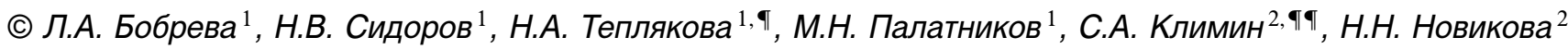 \\ ${ }^{1}$ Институт химии и технологии редких элементов и минерального сырья им. И.В. Тананаева \\ Федерального исследовательского центра „Кольский научный центр РАН“, \\ 184209 Апатиты, Мурманская обл., Россия \\ ${ }^{2}$ Институт спектроскопии РАН, \\ 108840 Москва, Троицк, Россия \\ e-mail: 『n.tepliakova@ksc.ru, "
}

Поступила в редакцию 09.06.2021 г.

В окончательной редакции 02.09.2021 г.

Принята к публикации 10.09.2021 г.

По ИК спектрам поглощения выполнен анализ комплексных дефектов, обусловленных наличием в структуре кристалла водородных связей, в номинально чистых кристаллах ниобата лития с разным отношением $\mathrm{Li} / \mathrm{Nb}$, в кристаллах, легированных магнием и цинком, в широком диапазоне концентраций $\left(\mathrm{LiNbO}_{3}: \mathrm{Mg}(0.19-5.91 \mathrm{~mol} \% \mathrm{MgO})\right.$ и $\mathrm{LiNbO}_{3}: \mathrm{Zn}(0.04-6.5 \mathrm{~mol} \% \mathrm{ZnO})$ ) и в кристаллах двойного легирования $\left(\mathrm{LiNbO}_{3}: \mathrm{Y}(0.24): \mathrm{Mg}(0.63 \mathrm{wt} . \%)\right.$ и $\mathrm{LiNbO}_{3}: \mathrm{Gd}(0.25): \mathrm{Mg}(0.75$ wt.\%)), полученных по технологии прямого легирования расплава, а также в кристалле двойного легирования $\left(\mathrm{LiNbO}_{3}: \mathrm{Mg}(5.05 \mathrm{~mol} \% \mathrm{MgO}): \mathrm{Fe}\left(0.009 \mathrm{~mol} \% \mathrm{Fe}_{2} \mathrm{O}_{3}\right)\right)$, выращенном из шихты, синтезированной с использованием технологии гомогенного легирования магнием и железом $\mathrm{Nb}_{2} \mathrm{O}_{5}$. Выявлено влияние легирующих примесей на концентрацию ОН-групп, вид и локализацию комплексных дефектов в структуре кристалла. Показано, что изменение количества позиций атомов водорода в структуре кристалла $\mathrm{LiNbO}_{3}$ позволяет с достаточной точностью судить о соответствии его состава стехиометрическому или конгруэнтному составу. Для легированных кристаллов разного состава получены данные, свидетельствующие об изменении при прохождении концентрационных порогов характера комплексообразования ОН-групп с точечными дефектами катионной подрешетки с образованием дефектов: $\mathrm{Me}_{\mathrm{Li}}-\mathrm{OH}^{-}, \mathrm{Me}_{\mathrm{Li}}-\mathrm{Me} \mathrm{Nb}-\mathrm{OH}$. При этом вследствие изменения механизма вхождения легирующего катиона в структуру кардинально изменяются свойства кристалла. Вклад в различие частот (и соответственно в значение квазиупругих постоянных связей $\mathrm{O}-\mathrm{H}$ ) в спектре конгруэнтного кристалла и легированных кристаллов может вносить также различие электроотрицательностей и ионных радиусов основных и легирующих катионов.

Ключевые слова: кристалл ниобата лития, легирование, комплексные и точечные структурные дефекты, ИК спектроскопия поглощения, валентные колебания ОН-групп.

DOI: $10.21883 /$ OS.2022.01.51904.12-21

\section{Введение}

Сегнетоэлектрический монокристалл ниобата лития $\left(\mathrm{LiNbO}_{3}\right)$ характеризуется высоким значением спонтанной поляризации, имеет высокие электрооптические, нелинейно-оптические коэффициенты, обладает хорошо регулируемым фоторефрактивным эффектом и является одним из универсальных функциональных материалов для генерации второй гармоники, электрооптических модуляторов, оптических переключателей, голографической записи информации $[1,2]$. Важным преимуществом ниобата лития является возможность управления физическими характеристиками кристалла в широких пределах путем варьирования состояния его дефектной структуры. Одной из особенностей кристаллов $\mathrm{LiNbO}_{3}$, выращенных в воздушной атмосфере, является присутствие в структуре дефектов в виде гидроксильных групп $\left(\mathrm{OH}^{-}\right)$[3-9]. Механизм включения атома водорода в кристаллическую решетку кристалла $\mathrm{LiNbO}_{3}$ не совсем понятен. Считается, что он входит в решетку из воздушной атмосферы во время роста кристалла $\mathrm{LiNbO}_{3}[3,10]$. Атом водорода вследствие малого размера и относительно слабая водородная связь обладают высокой чувствительностью к изменениям кристаллического поля, возникающим при изменении отношения $\mathrm{Li} / \mathrm{Nb}$ и легировании кристалла, что приводит к изменениям основных параметров полосы в ИК спектре поглощения в области валентных колебаний $\mathrm{OH}^{-}$-групп. Этот факт используется для изучения дефектной структуры кристалла.

Положение атомов водорода, связанных с атомом кислорода водородной связью, в структуре нестехиометрических кристаллов меняется в зависимости от вида и концентрации легирующей примеси. Присутствие атомов водорода в структуре кристалла $\mathrm{LiNbO}_{3}$ приводит к образованию с основными $\left(\mathrm{Nb}^{5+}\right.$ и $\left.\mathrm{Li}^{+}\right)$и легирующими катионами $(\mathrm{Me})$ комплексных дефектов: $V_{\mathrm{Li}}-\mathrm{OH}$, 
$\mathrm{Nb}_{\mathrm{Li}}-\mathrm{OH}, \mathrm{Me}-\mathrm{OH}, \mathrm{Me}-\mathrm{OH}-\mathrm{Me}[3-9]$. Наличие $\mathrm{OH}^{-}-$ групп играет важную роль в формировании вторичной структуры и физических характеристик кристалла: повышает низкотемпературную проводимость, понижает эффект фоторефракции и величину коэрцитивного поля [3,7]. Кристаллы $\mathrm{LiNbO}_{3}$, выращенные в разных условиях воздушной атмосферы по разным технологиям, содержат различные концентрации $\mathrm{OH}^{-}$-групп. Концентрацию $\mathrm{OH}^{-}$-групп можно изменять путем нагрева в соответствующей атмосфере кристаллов $\mathrm{LiNbO}_{3}[6]$.

Метод ИК спектроскопии в области валентных колебаний $\mathrm{OH}^{-}$-групп наиболее чувствителен к наличию и локализации $\mathrm{OH}^{-}$-групп в структуре кристалла. Данный метод позволяет изучать тонкие особенности реальной структуры кристаллов $\mathrm{LiNbO}_{3}$, обусловленные особенностями локализации в структуре атомов водорода. Это экспресс-метод для сопровождения технологий получения кристаллов ниобата лития, он менее трудоемкий, чем, например, метод рамановской спектроскопии, требует меньше времени для накопления сигнала при регистрации спектра, менее финансово затратный в обслуживании аппаратуры. Кроме того, метод ИК спектроскопии по интенсивности линий, соответствующих валентным колебаниям связей $\mathrm{O}-\mathrm{H}$, позволяет рассчитать концентрацию ОН-групп в структуре кристалла.

Целью настоящей работы было установление влияние состава кристалла на концентрацию $\mathrm{OH}^{-}$-групп и характер комплексных дефектов, связанных с ОН-группами, в номинально чистых кристаллах $\mathrm{LiNbO}_{3}$, близких к стехиометрическому $(\mathrm{Li} / \mathrm{Nb} \approx 1)$ и конгруэнтному $\left(\mathrm{LiNbO}_{3 \text { cong }}, \mathrm{Li} / \mathrm{Nb}=0.946\right)$ составов, а также в кристаллах $\mathrm{LiNbO}_{3}$ одинарного $\left(\mathrm{LiNbO}_{3}: \mathrm{Mg}(0.19-5.91 \mathrm{~mol} . \%\right.$ $\left.\mathrm{MgO}), \quad \mathrm{LiNbO}_{3}: \mathrm{Zn} \quad(0.04-6.5 \mathrm{~mol} \% \mathrm{ZnO})\right)$ и двойного $\quad\left(\mathrm{LiNbO}_{3}: \mathrm{Y} \quad(0.24): \mathrm{Mg}(0.63 \mathrm{wt} . \%), \quad \mathrm{LiNbO}_{3}: \mathrm{Gd}\right.$ $(0.25): \mathrm{Mg}\left(0.75\right.$ wt.\%), $\mathrm{LiNbO}_{3}: \mathrm{Mg}(5.05 \mathrm{~mol} . \% \mathrm{MgO}): \mathrm{Fe}$ $\left.\left(0.009 \mathrm{~mol} . \% \mathrm{Fe}_{2} \mathrm{O}_{3}\right)\right)$ легирования, полученных по разным технологиям.

Ранее исследование особенностей структуры кристаллов $\mathrm{LiNbO}_{3}$, обусловленных наличием дефектов в виде гидроксильных групп $\left(\mathrm{OH}^{-}\right)$, проводилось в работах [3-9]. Однако механизм кардинальной перестройки системы водородных связей в кристалле $\mathrm{LiNbO}_{3}$ при увеличении концентрации легирующей добавки до сих пор не ясен. Исследованные кристаллы ниобата лития отличаются количеством и типом точечных дефектов в виде глубоких и мелких электронных ловушек, степенью деформации легирующей добавкой кислородных октаэдров (определяющей их поляризуемость) и особенностями упорядочения структурных единиц катионной подрешетки вдоль полярной оси, а следовательно, нелинейнооптическими, электрическими и фоторефрактивными свойствами. Анализ ИК спектров реальных кристаллов ниобата лития разного состава и генезиса позволяет выявить возможности метода ИК спектроскопии в области колебаний ОН-групп для оценки структурного совершенства кристаллов ниобата лития, что актуаль- но для разработки методов сопровождения технологий выращивания монокристаллов ниобата лития.

\section{Результаты и их обсуждение}

\section{Расположение атома водорода в структуре кристалла $\mathrm{LiNbO}_{3}$}

В искаженной кислородной плоскости конгруэнтного кристалла $\mathrm{LiNbO}_{3}$ существует три различные длины O-О-связи $(272,288$ и $336 \mathrm{pm})$, что приводит к шести возможным позициям, на которых может расположиться атом водорода, связанный с атомом кислорода водородной связью [6]. Вопрос о позициях атомов водорода даже в структуре чистых нестехиометрических (с разным отношением $\mathrm{Li} / \mathrm{Nb}$ ) и легированных кристаллов ниобата лития на протяжении многих лет является предметом дискуссий [3-14]. Причем ситуация с легированными кристаллами намного сложнее. В легированных кристаллах (особенно в кристаллах двойного и большего легирования, где сложное распределение основных и легирующих катионов по кислородным октаэдрам, существенно зависящее от концентрации и вида легирующих катионов, и где существует более заметное искажение октаэдров легирующими катионами) локализация атомов водорода в структуре кристалла является особенно неоднозначной.

Для локализации атомов водорода, согласно данным работы [13], в структуре кристалла $\mathrm{LiNbO}_{3}$ имеются следующие позиции. Водород может замещать непосредственно ион $\mathrm{Li}^{+}$и находиться в центре кислородного октаэдра $\mathrm{O}_{6}$, а также может располагаться в центрах кислородных связей $\mathrm{O}-\mathrm{O}$ в октаэдре, занятом ионом $\mathrm{Li}^{+}$, или водородом, или легирующим ионом, в октаэдре, занятом ионом $\mathrm{Nb}^{5+}$ или легирующим ионом. Причем длины O-O-связей, на которых может располагаться водород, существенно различаются и зависят от состава кристалла, от степени искажения кислородных октаэдров $\mathrm{O}_{6}$ основными и легирующими катионами. С изменением концентрации легирующих катионов в кристалле будут изменяться характер распределения основных $\left(\mathrm{Li}^{+}\right.$и $\left.\mathrm{Nb}^{5+}\right)$ и легирующих катионов по октаэдрам и соответственно длины связей $\mathrm{O}-\mathrm{O}$, что должно приводить к изменению колебательного спектра в области валентных колебаний ОН-групп $\left(3500-3550 \mathrm{~cm}^{-1}\right)$ в ИК спектре, а также в спектре КРС в области колебаний ионов кислорода в кислородных октаэдрах $\left(500-900 \mathrm{~cm}^{-1}\right)$ и в области колебаний внутриоктаэдрических ионов $\left(150-300 \mathrm{~cm}^{-1}\right)$.

В литературе существуют несколько моделей локализации атомов водорода в структуре чистого конгруэнтного кристалла ниобата лития, основанных на расчетных данных, на данных ЯМР и данных ИК спектроскопии поглощения. На основании экспериментов по исследованию формы линий ЯМР в поликристалле конгруэнтного ниобата лития и расчетов второго момента линии ЯМР изотопа ${ }^{1} \mathrm{H}$ в работах $[12,15]$ было 
сделано заключение, что атом водорода должен быть расположен внутри вакантного октаэдра $V_{\mathrm{Li}} \mathrm{O}_{6}$ в центре самой длинной связи $\mathrm{O}-\mathrm{O}(336 \mathrm{pm})$. В то же время расчеты потенциального рельефа внутри элементарной ячейки стехиометрического кристалла ниобата лития на основе классического электростатического подхода с применением модифицированного метода точечных мультиполей, выполненные в работах $[13,16]$ методом компьютерного моделирования, свидетельствуют о том, что все гипотетические позиции атомов водорода, находящихся в центре связей $\mathrm{O}-\mathrm{O}$, являются неустойчивыми как в идеальной структуре, так и вблизи дефекта $V_{\mathrm{Li}}$. В то же время в работе [4] на основании данных ИК спектроскопии поглощения было сделано предположение, что атомы водорода в чистом конгруэнтном кристалле располагаются в плоскости атомов кислорода на самых коротких связях О-O (272 pm). При этом считается, что самая длинная О-О-связь (336 pm) не занята водородом. Однако этот вывод, по-видимому, можно считать ненадежным, поскольку авторы в расчетах предполагали, что кристалл ниобата лития имеет структуру перовскита, в которой кислородные октаэдры соединены вершинами. На самом деле кристалл ниобата лития относится к гораздо более жесткой структуре псевдоильменита с плотнейшей гексагональной упаковкой, в которой кислородные октаэдры соединены ребрами [17-19]. Согласно данным работ [20,21], основанных на анализе ИК спектров поглощения, предполагается, что атом водорода располагается в верхнем кислородном треугольнике октаэдра $\mathrm{NbO}_{6}$, при этом дипольный момент группы $\mathrm{OH}^{-}$направлен вдоль короткой связи $\mathrm{O}-\mathrm{O}$, а длина связи $\mathrm{O}-\mathrm{H}$ составляет $98.8 \mathrm{pm}$ [20]. В работе [4] рассматривается модель, в которой анализируются четыре различных положения атома водорода в структуре кристалла ниобата лития. В этой модели водород располагается на двух коротких O-O-связях перпендикулярно оси Z. Расположение водорода вдоль длинной О-О-связи (336 pm) при этом исключается вследствие того, что расстояние между атомом водорода и ионом кислорода более $99 \mathrm{pm}$ недостаточно для образования водородной связи и возможно только электростатическое взаимодействие. Кроме того, на такую слабую связь будут влиять распределение заряда и ионная поляризуемость ближайших ионов, еще более ее ослабляя. В модели, описанной в работе [4], рассматривается пять энергетически различных позиций атомов водорода в кристалле. Однако в этой модели рассматриваются не учитываемые взаимодействия водорода с другими ионами, помимо образования гидроксильной группы. Появление двух высоких энергетических зон может быть следствием внутренних дефектов из-за дефицита Li в кристалле.

Выполненное в работе [22] компьютерное моделирование положения атома водорода в приближении Борна-Оппенгеймера с целью определения расположения наиболее стабильной конфигурации дефектного кластера с $\mathrm{OH}^{-}$-группой в структуре кристалла $\mathrm{LiNbO}_{3}$ показало, что в самой стабильной конфигурации водород не находится ни на линии, ни вблизи линии О-О-связи, но расположен вблизи биссектрисы $(3.36 \AA)$ кислородного треугольника и наклонен от кислородной плоскости в сторону литиевой вакансии $V_{\mathrm{Li}}$ на $4.3^{\circ}$. Длина равновесной ОН-связи при этом составляет $0.988 \AA$ А. Эти результаты согласуются с результатами предыдущего теоретического исследования [23] и с результатами экспериментов ИК спектроскопии в поляризованном излучении [24]. Положение атомов водорода, связанных с атомом кислорода водородной связью, в структуре нестехиометрических кристаллов меняется в зависимости от отношения $\mathrm{Li} / \mathrm{Nb}$, вида и концентрации легирующей примеси [6,11,24-29].

\section{Водородные связи в стехиометрических и конгруэнтных кристаллах $\mathrm{LiNbO}_{3}$}

Наличие в структуре монокристалла ниобата лития различных позиций атомов водорода, связанных с атомом кислорода водородной связью, приводит к изменению количества и параметров полос в спектре ИК поглощения в области валентных колебаний водородных связей. В идеальном стехиометрическом кристалле $\mathrm{LiNbO}_{3}$, где отношение $\mathrm{Li} / \mathrm{Nb}=1$, катионы $\mathrm{Li}^{+}$и $\mathrm{Nb}^{5+}$ занимают свои основные позиции в кристаллической решетке и полностью отсутствуют точечные дефекты ниобия в литиевой позиции $\mathrm{Nb}_{\mathrm{Li}}$ и вакансии лития $V_{\mathrm{Li}}$. Согласно данным работ $[3,28]$, в кристаллической решетке таких кристаллов не существует возможной позиции, которую мог бы занять атом водорода, связанный с атомом кислорода водородной связью. В связи с этим в области частот валентных колебаний в ИК спектрах поглощения идеального стехиометрического кристалла не должно быть полос поглощения, связанных с $\mathrm{OH}^{-}$группами.

В структуре реального высокоупорядоченного стехиометрического монокристалла (даже при строгом отношении $\mathrm{Li} / \mathrm{Nb}=1$ ) возможны точечные дефекты в виде рядом стоящих одноименных катионов или вакансий, а также связанные с ними комплексные дефекты, которые обусловлены присутствием атома водорода, связанного с атомом кислорода водородной связью в структуре монокристалла. В работах $[3,30]$ были изучены реальные кристаллы $\mathrm{LiNbO}_{3}$ с разным отношением $\mathrm{Li} / \mathrm{Nb}$, полученные методом HTTSSG (High temperature top seeded solution growth), из расплава конгруэнтного состава с использованием флюса $\mathrm{K}_{2} \mathrm{O}$, приведены результаты исследования о влиянии состава кристалла на частоту и форму полос поглощения в ИК спектре в области частот валентных колебаний $\mathrm{OH}^{-}$-групп. По полученным данным [3,30] для номинально чистого конгруэнтного кристалла $(\mathrm{Li} / \mathrm{Nb}=0.946)$ в ИК спектре регистрировалась широкая полоса поглощения - ее ширина около $30 \mathrm{~cm}^{-1}$, которая имеет расщепление на несколько компонентов с частотами 3467,3483 и $3488 \mathrm{~cm}^{-1}$. Чем ближе состав кристалла $\mathrm{LiNbO}_{3}$ к стехиометрическому, 
тем меньше становилась полуширина полос поглощения с частотами 3466,3480 и $3488 \mathrm{~cm}^{-1}$. Для реального высокоупорядоченного стехиометрического кристалла $(\mathrm{Li} / \mathrm{Nb}=1)$ в ИК спектре наблюдалась единственная узкая полоса поглощения, ширина которой равна $3 \mathrm{~cm}^{-1}$, с частой $3466 \mathrm{~cm}^{-1}$. В работе [30] считают, что наличие полосы поглощения $3466 \mathrm{~cm}^{-1}$ связано с образованием комплексного дефекта $\mathrm{OH}_{\mathrm{Li}}^{-}$, где водород занимает основную позицию Li. Данные работы [5] имеют схожий вывод о позиции атома водорода в структуре кристалла $\mathrm{LiNbO}_{3}$, только предполагается, что позиция лития, которую замещает атом водорода, располагается около длинной кислородной связи (336 pm). В работе [5] высказано предложение, что номинально чистый стехиометрический кристалл $\mathrm{LiNbO}_{3}$ можно рассматривать как кристалл, легированный металлической примесью $\mathrm{Me}^{5+}$. Такой легирующей примесью $\mathrm{Me}^{5+}$ можно считать ионы $\mathrm{Nb}^{5+}$, расположенные не в своих позициях. Несмотря на отношение главных компонентов $\mathrm{Li} / \mathrm{Nb}=1$, в структуре кристалла стехиометрического состава $\mathrm{LiNbO}_{3}$ существуют точечные дефекты катионной подрешетки в виде рядом стоящих одноименных катионов $\mathrm{Nb}^{5+}$. По мнению авторов [5], полоса поглощения с частотой $3466 \mathrm{~cm}^{-1}$ соответствует валентным колебаниям $\mathrm{OH}^{-}$группы в комплексном дефекте $\mathrm{Me}_{\mathrm{Nb}}^{5+}-\mathrm{OH}^{-}$. По данным работы [12] в ИК спектре поглощения кристалла $\mathrm{LiNbO}_{3}$ конгруэнтного состава в области валентных колебаний водородных связей регистрировались полосы поглощения с частотами 3481 и $3489 \mathrm{~cm}^{-1}$, которые соответствуют комплексному дефекту $\left(V_{\mathrm{Li}}\right)-\mathrm{OH}$. Атом водорода, по мнению авторов работы [12], располагается в вакантных октаэдрах, где ранее находились катионы лития $\left(V_{\mathrm{Li}}\right)$.

При любом отклонении от стехиометрии $(\mathrm{Li} / \mathrm{Nb} \neq 1)$ в спектре ИК поглощения наблюдаются несколько (не более шести) более широких полос, свидетельствующих о нескольких позициях атомов водорода в структуре кристалла. Таким образом, изменение количества позиций атомов водорода в структуре монокристалла $\mathrm{LiNbO}_{3}$ позволяет с достаточной точностью судить о соответствии его состава стехиометрическому составу $(\mathrm{Li} / \mathrm{Nb}=1)$. В работах $[31,32]$ были проанализированы спектры ИК поглощения в области частот валентных колебаний $\mathrm{OH}^{-}$-групп кристаллов $\mathrm{LiNbO}_{3 \text { cong }}, \mathrm{LiNbO}_{3 \text { stoich, }}$, $\mathrm{LiNbO}_{3 \text { stoich }}: \mathrm{K}_{2} \mathrm{O}$ (4.5 wt.\%), $\mathrm{LiNbO}_{3 \text { stoich }}: \mathrm{K}_{2} \mathrm{O}$ (6.0 wt.\%), а также ИК спектры, полученные в работе [3] (рис. 1). В работах $[31,32]$ для номинально чистого конгруэнтного кристалла $\mathrm{LiNbO}_{3 \text { cong }}(\mathrm{Li} / \mathrm{Nb}=0.946)$ наблюдаются полосы поглощения с частотами 3470,3483 и $3486 \mathrm{~cm}^{-1}$; для кристаллов $\mathrm{LiNbO}_{3 \text { stoich }}: \mathrm{K}_{2} \mathrm{O}$, полученных методом HTTSSG, в отличие от данных работ [3,30] (где кристаллы также выращивались методом HTTSSG) в ИК спектре в области частот валентных колебаний $\mathrm{OH}^{-}$групп наблюдается не одна, а три полосы одинаковой поляризации с частотами 3465,3480 и $3488 \mathrm{~cm}^{-1}$ (рис. 1). Данный факт позволяет сделать вывод, что структура выращенных нами методом HTTSSG кристал-

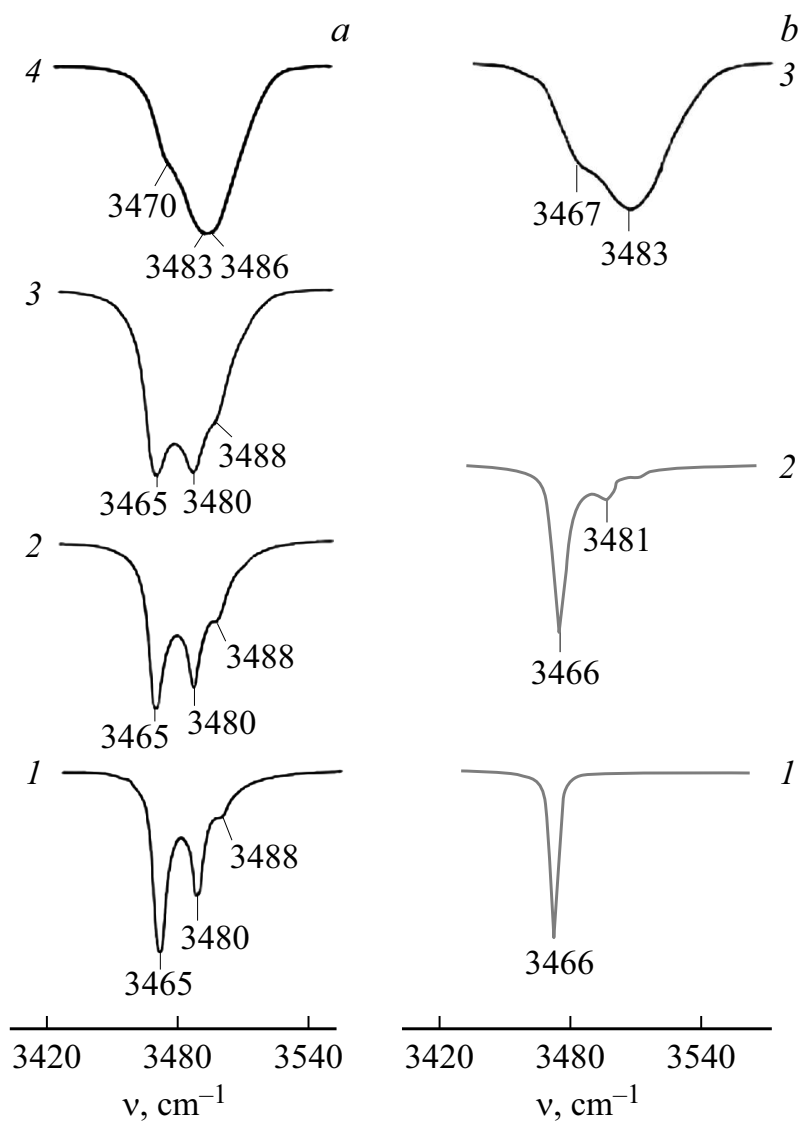

Рис. 1. (a) ИК спектры поглощения (в относительных единицах) в области частот валентных колебаний $\mathrm{OH}^{-}$групп кристаллов: $1-\mathrm{LiNbO}_{3 \text { stoich }}, 2-\mathrm{LiNbO}_{3 \text { stoich }}$ $\left(6.0\right.$ wt. $\left.\% \quad \mathrm{~K}_{2} \mathrm{O}\right), 3-\mathrm{LiNbO}_{3 \text { stoich }}\left(4.5\right.$ wt. $\left.\% \mathrm{~K}_{2} \mathrm{O}\right), 4-$ $\mathrm{LiNbO}_{3 \text { cong }}(\mathrm{Li} / \mathrm{Nb}=0.946) \quad[30,31] ;(b)$ ИК спектры поглощения кристаллов, выращенных способом HTTSSG с использованием флюса $\mathrm{K}_{2} \mathrm{O}: 1-\mathrm{LiNbO}_{3 \text { stoich }}\left(12.1 \mathrm{wt} . \% \mathrm{~K}_{2} \mathrm{O}\right)$, 2 - $\mathrm{LiNbO}_{3 \text { stoich }}\left(9.35 \mathrm{wt} . \% \mathrm{~K}_{2} \mathrm{O}\right)$, а также кристалла: 3 $\mathrm{LiNbO}_{3 \text { cong }}\left(48.7 \mathrm{~mol} \% \mathrm{Li}_{2} \mathrm{O}\right)[3]$.

лов $\mathrm{LiNbO}_{3 \text { stoich }}: \mathrm{K}_{2} \mathrm{O}$ является промежуточной между структурой кристаллов стрехиометрического и конгруэнтного составов. С приближением структуры кристалла к стехиометрическому составу $(\mathrm{Li} / \mathrm{Nb} \approx 1)$ в ИК спектрах регистрируется сужение полос и понижение интенсивностей полос с частотами 3480 и $3488 \mathrm{~cm}^{-1}$ (рис. 1). Таким образом, данные работ [31,32] имеют отличие от данных, представленных в работах [3,30], в которых кристаллы также выращивались методом HTTSSG, но в которых в ИК спектре поглощения реального высокоупорядоченного стехиометрического кристалла регистрируется всего лишь 1 полоса поглощения с частотой $3466 \mathrm{~cm}^{-1}$ (рис. 1). Это говорит о том, что в реальном высокоупорядоченном стехиометрическом кристалле, в котором практически отсутствуют дефекты $\mathrm{Nb}_{\mathrm{Li}}$, позиции гидроксильных групп эквивалентны и в структуре есть только одно значение квазиупругой постоянной связи О-Н. Причем это значение меньше 
значений квазиупругих постоянных связей $\mathrm{O}-\mathrm{H}$ в нестехиометрических кристаллах. Эта особенность структуры обусловлена тем, что в высокоупорядоченном стехиометрическом кристалле кислородные октаэдры структуры практически не искажены и близки к идеальным. В стехиометрическом кристалле, близком к идеальному, все октаэдры (октаэдр, в котором находится $\mathrm{Nb}$; октаэдр, в котором находится $\mathrm{Li}$, и вакантный октаэдр) практически эквивалентны (расстояния О-О практически равны), а катионная подрешетка гораздо более упорядочена по сравнению с катионной подрешеткой кристаллов $\mathrm{LiNbO}_{3}$ любого другого состава $[2,3]$.

Катионная подрешетка кристаллов, выращенных из расплава конгруэнтного состава, является гораздо более разупорядоченной, чем катионная подрешетка стехиометрических образцов, прежде всего ввиду наличия дефектов $\mathrm{Nb}_{\mathrm{Li}}$, являющихся наиболее глубокими ловушками электронов. Точечные дефекты катионной подрешетки в кристаллах $\mathrm{Nb}_{\mathrm{Li}}, V_{\mathrm{Li}}$ и др. вследствие изменения длин О-О-связи при образовании дефекта приводят не только к нарушению порядка следования структурных единиц катионной подрешетки вдоль полярной оси, но и к „возмущению“ кислородных октаэдров $\mathrm{O}_{6}[24,31,33-35]$. При этом степень „возмущения" октаэдров (вакантных, а также занятых катионами $\mathrm{Li}^{+}$и $\mathrm{Nb}^{5+}$ ) и длины расстояний $\mathrm{O}-\mathrm{O}$ в октаэдрах существенно зависят от величины $\mathrm{Li} / \mathrm{Nb}$, которая, собственно, и определяет количество точечных дефектов $\mathrm{Nb}_{\mathrm{Li}}$ и $V_{\mathrm{Li}}$ и др. в беспримесных кристаллах. Благодаря наличию в кристалле $\mathrm{LiNbO}_{3}$ водорода эти точечные дефекты образуют комплексы с $\mathrm{OH}^{-}$-группами. Именно эти особенности структуры обусловливают тот факт, что в близких к идеальному стехиометрических кристаллах позиции всех $\mathrm{OH}^{-}$-групп и квазиупругие постоянные связи $\mathrm{O}-\mathrm{H}$ в октаэдрах, занятых катионами $\mathrm{Li}^{+}, \mathrm{Nb}^{5+}$, и в вакантных октаэдрах практически одинаковы. Это уверенно подтверждается и исследованиями $[31,32]$. Присутствие трех полос в спектре ИК поглощения кристаллов $\mathrm{LiNbO}_{3 \text { cong }}, \mathrm{LiNbO}_{3 \text { stoich }}, \mathrm{LiNbO}_{3 \text { stoich }}\left(4.5\right.$ wt.\% $\left.\mathrm{K}_{2} \mathrm{O}\right)$, $\mathrm{LiNbO}_{3 \text { stoich }}\left(6.0 \mathrm{wt} \% \mathrm{~K}_{2} \mathrm{O}\right)$ свидетельствует о наличии трех центров, в которых могут локализоваться атомы водорода, связанные с атомами кислорода водородной связью. Точечные дефекты $\mathrm{Nb}_{\mathrm{Li}}, V_{\mathrm{Li}}$ и вакантные октаэдры идеальной структуры $(V)$ являются этими центрами и формируют комплексные дефекты с $\mathrm{OH}^{-}$-группами. Стоит отметить, что спектры кристаллов $\mathrm{LiNbO}_{3 \text { stoich }}$ и $\mathrm{LiNbO}_{3 \text { stoich }}\left(6.0 \mathrm{wt.} \% \mathrm{~K}_{2} \mathrm{O}\right)$ практически идентичны, что свидетельствует об одинаковой локализации $\mathrm{OH}^{-}$-групп в структуре этих кристаллов и об одинаковых значениях квазиупругих постоянных связей $\mathrm{O}-\mathrm{H}$.

\section{Водородные связи в легированных кристаллах $\mathrm{LiNbO}_{3}$}

Тип и концентрация легирующей примеси в кристалле $\mathrm{LiNbO}_{3}$ существенно влияют на формирование и вид комплексных дефектов, обусловленных наличием водородных связей, и физические характеристики кристалла $[3,6,7]$. Так, существование точечных и связанных с ними комплексных дефектов, обусловленных наличием в кристалле многозарядных (фоторефрактивных) катионов ( $\mathrm{Fe}, \mathrm{Cu}$ и др.), оказывает влияние на композиционную однородность и стойкость кристалла к повреждению оптическим излучением $[10,12]$. Во всех случаях присутствие комплексных дефектов повышает низкотемпературную проводимость, понижает эффект фоторефракции и величину коэрцитивного поля $[3,6,12]$. Для понимания механизма образования комплексных дефектов и исследования динамики их локализации в кристалле с изменением концентрации примеси необходимо учитывать валентность (степень окисления), электроотрицательность и ионный радиус легирующих добавок. Когда существует несколько видов легирующих примесей в кристалле $\mathrm{LiNbO}_{3}$, возможна конкуренция во взаимодействии за занятие позиций примесями в структуре кристалла.

\section{Водородные связи в кристаллах $\mathrm{LiNbO}_{3}$ одинарного легирования}

Легирование „нефоторефрактивными“ добавками Mg, $\mathrm{Zn}, \mathrm{Sc}, \mathrm{In}$ и др. приводит к уменьшению эффекта фоторефракции и величины коэрцитивного поля в кристалле $\mathrm{LiNbO}_{3}$. При легировании кристалла $\mathrm{LiNbO}_{3}$ с изменением концентрации примеси происходит не только изменение отношения $\mathrm{Li} / \mathrm{Nb}$, но и перераспределение по октаэдрам основных (литий, ниобий) и примесных катионов. Рост концентрации легирующих нефоторефрактивных добавок в кристалле $\mathrm{LiNbO}_{3 \text { cong }}$ сопровождается двумя механизмами регулирования порядка расположения структурных единиц катионной подрешетки (механизм упорядочения и механизм разупорядочения), находящимися в условиях конкуренции. Взаимодействие этих механизмов отчасти обусловливает наличие концентрационных порогов легирующих элементов $\mathrm{Zn}$ и $\mathrm{Mg}$ в кристаллах $\mathrm{LiNbO}_{3}$, при переходе через которые (вследствие изменения механизма вхождения легирующего катиона в структуру) кардинально изменяются свойства кристалла $[2,7,10,36]$.

На рис. 2 представлены спектры ИК поглощения в области частот валентных колебаний $\mathrm{OH}^{-}$групп кристалла $\mathrm{LiNbO}_{3 \mathrm{cong}}$, a также серии монокристаллов $\mathrm{LiNbO}_{3}: \mathrm{Mg} \quad(0.19-5.91 \mathrm{~mol} \% \% \mathrm{MgO})$ и $\mathrm{LiNbO}_{3}: \mathrm{Zn}(0.04-4.54 \mathrm{~mol} . \% \mathrm{ZnO})$. Диапазон концентраций $0.19-5.91 \mathrm{~mol} \% \mathrm{MgO}$ захватывает концентрационные пороги при 3.0 и $5.5 \mathrm{~mol} \% \mathrm{MgO}$ [2]. Диапазон концентраций $0.04-6.5 \mathrm{~mol} . \% \mathrm{ZnO}$ захватывает концентрационные пороги при 5.3 и $6.8 \mathrm{~mol} . \% \mathrm{ZnO}$ в расплаве [37].

Дефектную структуру кристалла и образование $\mathrm{O}-\mathrm{H}$ связей возможно описать с помощью вакансионных сплит-моделей, используя данные полнопрофильного 


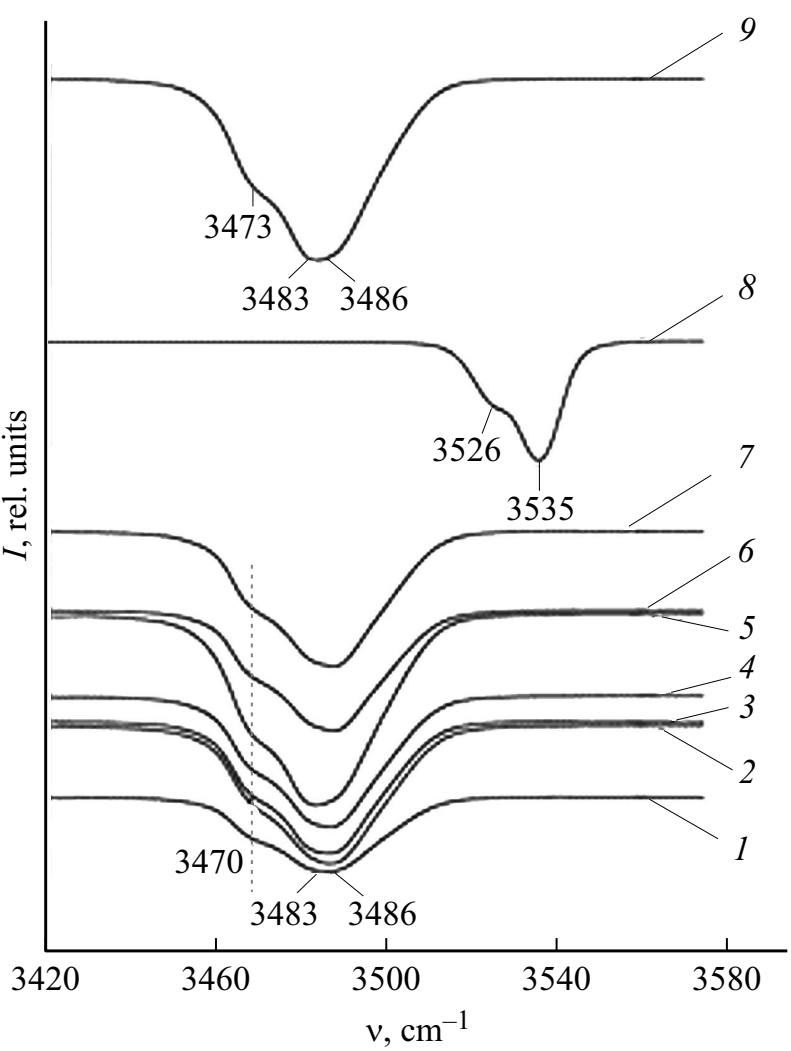

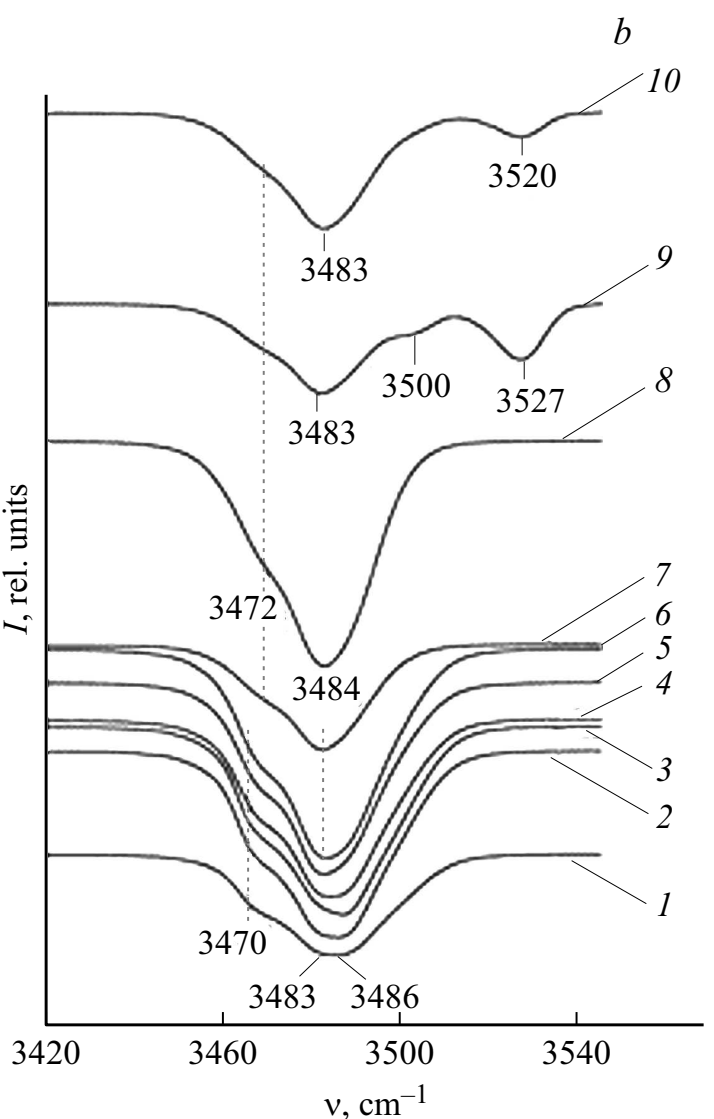

Pис. 2. Спектры ИК поглощения монокристаллов в области частот валентных колебаний $\mathrm{OH}^{-}$-групп $(a): 1-\mathrm{LiNbO}_{3 \text { cong }}$ $(\mathrm{Li} / \mathrm{Nb}=0.946), 2-\mathrm{LiNbO}_{3}: \mathrm{Mg}(0.19), 3-\mathrm{LiNbO}_{3}: \mathrm{Mg}(0.48), 4-\mathrm{LiNbO}_{3}: \mathrm{Mg}(1.53), 5-\mathrm{LiNbO}_{3}: \mathrm{Mg}(1.65), 6-$ $\mathrm{LiNbO}_{3}: \mathrm{Mg}(2.13), 7-\mathrm{LiNbO}_{3}: \mathrm{Mg}(3.02), 8-\mathrm{LiNbO}_{3}: \mathrm{Mg}(5.29), 9-\mathrm{LiNbO}_{3}: \mathrm{Mg}\left(5.91\right.$ mol.\% MgO); (b): $1-\mathrm{LiNbO}_{3 \text { cong }}$ $(\mathrm{Li} / \mathrm{Nb}=0.946), 2-\mathrm{LiNbO}_{3}: \mathrm{Zn}(0.04), 3-\mathrm{LiNbO}_{3}: \mathrm{Zn}(0.07), 4-\mathrm{LiNbO}_{3}: \mathrm{Zn}(1.19), 5-\mathrm{LiNbO}_{3}: \mathrm{Zn}(1.40), 6-\mathrm{LiNbO}_{3}: \mathrm{Zn}(2.01)$, $7-\mathrm{LiNbO}_{3}: \mathrm{Zn}(4.46 \mathrm{~mol} . \%), 8-\mathrm{LiNbO}_{3}: \mathrm{Zn}(4.54), 9-\mathrm{LiNbO}_{3}: \mathrm{Zn}(4.68), 10-\mathrm{LiNbO}_{3}: \mathrm{Zn}\left(6.5 \mathrm{~mol}_{0} \% \mathrm{ZnO}\right.$ в кристалле).

рентгеноструктурного анализа [38]. Согласно сплитмодели компенсации Li-вакансий, в кристаллической решетке $\mathrm{LiNbO}_{3 \text { cong }}$ происходит частичное замещение одного иона лития ионом ниобия с образованием четырех литиевых вакансий [3,39]. Структура дефектного комплекса в модели литиевых вакансий состоит из точечного дефекта $\mathrm{Nb}_{\mathrm{Li}}$, окруженного тремя точечными дефектами $V_{\mathrm{Li}}$ в ближайших окрестностях, и одного точечного дефекта $V_{\mathrm{Li}}-\mathrm{OH}$. Этот дефектный комплекс обладает электрическим дипольным моментом, направленным вдоль оси $Z$ [26]. Отрицательно заряженные точечные дефекты $\left(V_{\mathrm{Li}}\right)^{-}$притягивают атом водорода, связанный с атомом кислорода водородной связью, который располагается на длинных О-О-связях (336 pm). Таким образом, согласно данным работы [9], формируются комплексные дефекты $V_{\mathrm{Li}}-\mathrm{OH}$, которым соответствуют полосы поглощения с частотами 3483 и $3486 \mathrm{~cm}^{-1}$ (рис. 2, кривая 1).

При концентрации в области первого порогового значения $\sim 3.0 \mathrm{~mol} . \% \mathrm{MgO}$ для кристаллов $\mathrm{LiNbO}_{3}: \mathrm{Mg}$ и в области концентрационного порога $\sim 6.76 \mathrm{~mol} . \% \mathrm{ZnO}$ в расплаве для кристаллов $\mathrm{LiNbO}_{3}: \mathrm{Zn}$ не образуется новых комплексных дефектов. Это обусловлено тем, что легирующая добавка $(\mathrm{Mg}, \mathrm{Zn})$ замещает дефекты $\mathrm{Nb}_{\mathrm{Li}}$, образуя дефекты $\left(\mathrm{Mg}_{\mathrm{Li}}^{+}, \mathrm{Zn}_{\mathrm{Li}}^{+}\right)$, которые по отношению к кристаллической решетке положительно заряжены и не могут притягивать к себе атомы водорода с образованием новых комплексных дефектов. Таким образом, ИК спектры поглощения в области частот валентных колебаний водородных связей серии кристаллов $\mathrm{LiNbO}_{3}: \mathrm{Mg}$ и $\mathrm{LiNbO}_{3}: \mathrm{Zn}$ в области первых „поровых“ значений будут схожи с ИК спектром номинально чистого кристалла конгруэнтного состава $\mathrm{LiNbO}_{3 \text { cong }}$ (рис. 2, $a$, кривые $1-7$ и рис. 2, $b$, кривые 1-8).

С увеличением концентрации легирующей примеси магния вблизи второго концентрационного порога $(\sim 5.5 \mathrm{~mol} . \% \mathrm{MgO})$ дефекты $\mathrm{Nb}_{\mathrm{Li}}$ будут вытеснены катионами $\mathrm{Mg}^{2+}$, и в дальнейшем катионы $\mathrm{Mg}^{2+}$ начнут занимать позиции катионов $\mathrm{Li}^{+}$и $\mathrm{Nb}^{5+}$ идеальной стехиометрической структуры, формируя точечные дефекты $\mathrm{Mg}_{\mathrm{Li}}^{+}$и $\mathrm{Mg}_{\mathrm{Nb}}^{3-}$, которые образуют самокомпенсирующиеся пары $\mathrm{Mg}_{\mathrm{Li}}^{+}-\mathrm{Mg}_{\mathrm{Nb}}^{3-}$, имеющие большую силу притяжения для атома водорода. Таким образом, атом водорода будет выходить из дефекта $\left(V_{\mathrm{Li}}\right)-\mathrm{OH}^{-}$ 
и начнет участвовать в формировании комплексного дефекта $\mathrm{Mg}_{\mathrm{Li}}^{+}-\mathrm{Mg}_{\mathrm{Nb}}^{3-}-\mathrm{OH}$, которому соответствуют полосы поглощения с частотами 3526 и $3535 \mathrm{~cm}^{-1}$. Появление данных особенностей структуры приводит также к сдвигу полос поглощения в ИК спектре в область высоких частот (рис. 2, $a$, кривая 8). Однако после прохождения второго концентрационного порога ( $5.5 \mathrm{~mol} . \% \mathrm{MgO})$ спектр ИК поглощения практически идентичен спектру кристаллов с концентрацией магния ниже первого порогового значения (рис. 2, $a$, кривая 10). В работах $[26,40]$ сдвиг полос поглощения в ИК спектре сильно легированных монокристаллов $\mathrm{LiNbO}_{3}: \mathrm{Mg}$ (> $5.5 \mathrm{~mol} \% \mathrm{MgO}$ ) связывают с образованием дополнительных фаз ниобатов магния - фазы $\mathrm{Mg}_{4} \mathrm{Nb}_{2} \mathrm{O}_{9}$. Вопрос о существовании дополнительной фазы ниобата лития выше второго концентрационного порога является дискуссионным, поскольку в настоящее время ввиду малой концентрации этой фазы в кристалле нет прямых методов ее определения. Концентрация этой фазы (если она есть в кристалле) чрезвычайно низка и не может быть обнаружена даже методами полнопрофильного рентгеноструктурного анализа в сочетании с расчетами с использованием сплит-моделей катионной подрешетки кристалла ниобата лития. Косвенно о наличии этой фазы (но только предположительно) можно судить по ИК спектрам поглощения в области валентных колебаний ОН-групп.

$\mathrm{B}$ кристаллах $\mathrm{LiNbO}_{3}$ с концентрацией цинка, превышающей пороговую $\sim 6.76 \mathrm{~mol} \% \mathrm{ZnO}$, также происходит перестройка структуры катионной подрешетки. Катионы цинка начинают вытеснять катионы ниобия из собственных позиций $\mathrm{Nb}_{\mathrm{Nb}}$, образуя точечные дефекты $\mathrm{Zn}_{\mathrm{Nb}}$. При этом наблюдаются существенные изменения в спектрах ИК поглощения в области валентных колебаний $\mathrm{OH}^{-}$-групп (рис. 2, $b$, кривая 9). Отрицательно заряженные точечные дефекты $\mathrm{Zn}_{\mathrm{Nb}}^{3-}$ способны локализовать ионы водорода, образуя комплексный дефект $\mathrm{Zn}_{\mathrm{Nb}}-\mathrm{OH}$. Этому комплексному дефекту в спектре ,послепорогового“ кристалла $\mathrm{LiNbO}_{3}: \mathrm{Zn}(4.68 \mathrm{~mol} . \% \mathrm{ZnO}$ в кристалле) соответствуют полосы поглощения с частотами $\sim 3500$ и $3527 \mathrm{~cm}^{-1}$ (рис. 2, $b$, кривая 9). Наличие этих полос поглощения характерно для всех „послепороговых“ кристаллов $\mathrm{LiNbO}_{3}: \mathrm{Zn}$, выращенных из расплава с концентрацией $\mathrm{ZnO} \geq 6.76 \mathrm{~mol} \%$. Так, для кристалла $\mathrm{LiNbO}_{3}: \mathrm{Zn}(6.5 \mathrm{~mol} . \% \mathrm{ZnO}$ в кристалле) о наличии комплексных дефектов $\mathrm{Zn}_{\mathrm{Nb}}-\mathrm{OH}$ свидетельствует присутствие в спектре полосы поглощения с частотой $3520 \mathrm{~cm}^{-1}$ (рис. $2, b$, кривая 10 ).

\section{Водородные связи в кристаллах $\mathrm{LiNbO}_{3}$ двойного легирования}

Согласно данным работ [3,37], двойное легирование кристаллов $\mathrm{LiNbO}_{3}$ „нефоторефрактивными“ и „фоторефрактивными“ катионами дает возможность более тонко регулировать упорядочение структурных единиц

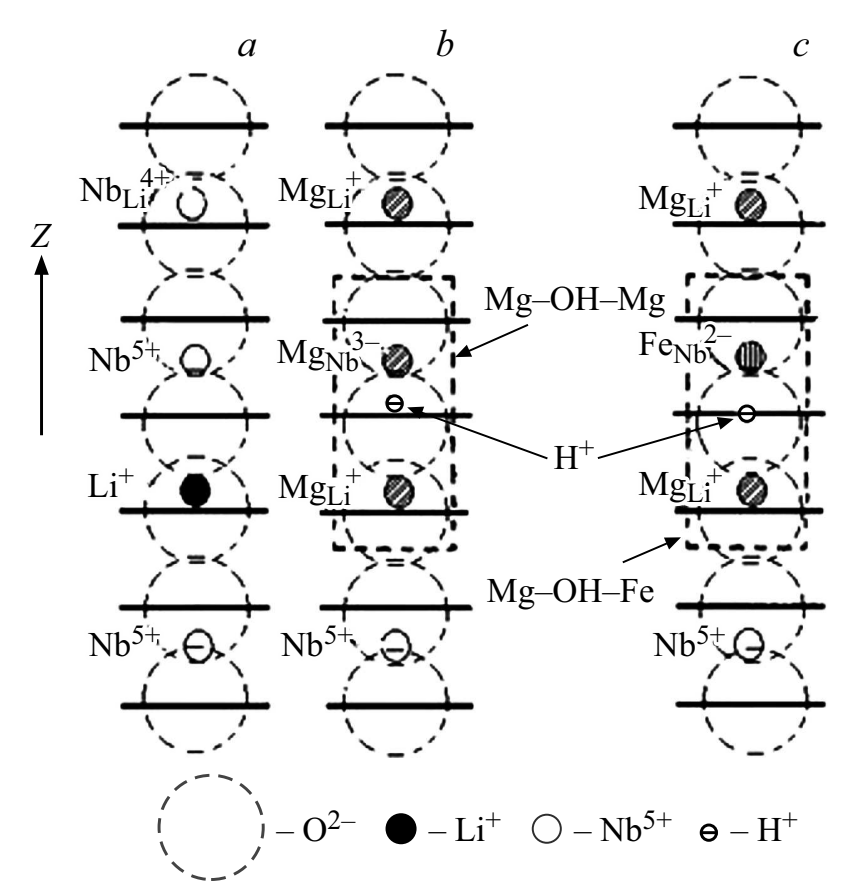

Рис. 3. Дефектная структура кристаллов: $\mathrm{LiNbO}_{3 \text { cong }}$ $\left(\begin{array}{lllll}(\mathrm{Li} / \mathrm{Nb}=0.946) & (\text { a }) & \text { и } \quad \mathrm{LiNbO}_{3}: \mathrm{Mg} \quad(5.05 \mathrm{~mol} \% & \mathrm{MgO}): \mathrm{Fe}\end{array}\right.$ $\left(0.009\right.$ mol. $\left.\% \mathrm{Fe}_{2} \mathrm{O}_{3}\right)(b, c)$.

катионной подрешетки, искажение легирующими примесями кислородных октаэдров $\mathrm{O}_{6}$, определяющих величину спонтанной поляризации и сегнетоэлектрические свойства кристалла, а также изменять тип и количество дефектов с локализованными электронами, определяющими величину эффекта фоторефракции [3]. Таким образом, при двойном легировании монокристалл $\mathrm{LiNbO}_{3}$ может получиться более композиционно однородным, чем при одинарном легировании [37]. Наличие фотовольтаических активных примесей в виде многозарядных катионов переходных металлов (например, Fe), влияет на композиционную однородность и оптическую стойкость кристалла [3,41-43]. Применяя двойное легирование, когда одна из добавок является „фоторефрактивной““, возможно создавать материалы для оптики с минимальным временем фоторефрактивного отклика и повышенной стойкостью к оптическому повреждению [44].

В кристалле $\mathrm{LiNbO}_{3}$ атом водорода размещается вблизи отрицательно заряженных точечных дефектных центров вследствие малого размера и достаточно большой скорости диффузии. На рис. 3 представлена модель расположения комплексных дефектов в структуре конгруэнтного кристалла $\mathrm{LiNbO}_{3}: \mathrm{Mg}: \mathrm{Fe}$. Рис. 3 получен на основе общих закономерностей вхождения легирующих добавок в структуру конгруэнтного кристалла $\mathrm{LiNbO}_{3}$, исследованных в работах [2,10], а также на основе рассуждений о наличии и расположении в кристалле $\mathrm{LiNbO}_{3}$ атома водорода [4]. В кристалле $\mathrm{LiNbO}_{3}: \mathrm{Mg}: \mathrm{Fe}$, легированном магнием выше второго концентрационного порога $(5.5 \mathrm{~mol} \% \mathrm{MgO}$ в распла- 


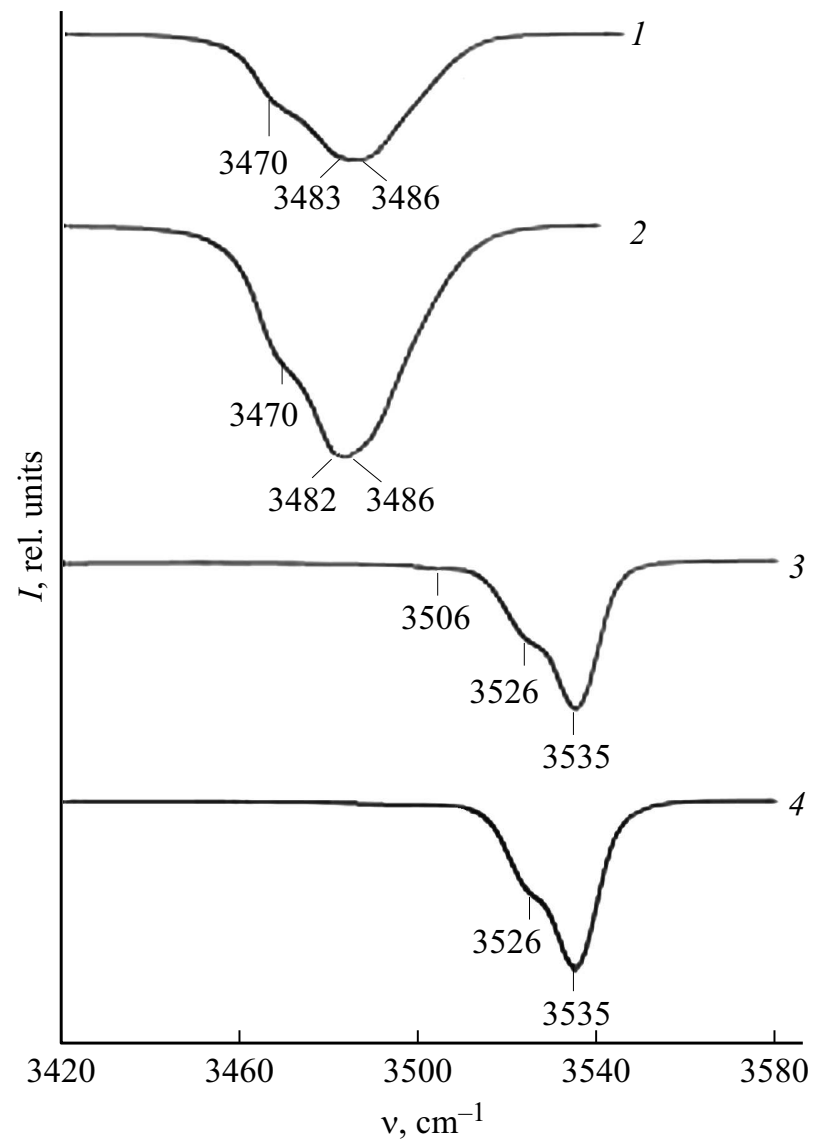

Рис. 4. Спектры ИК поглощения монокристаллов ниобата лития в области частот валентных колебаний $\mathrm{OH}^{-}$групп: $1-\mathrm{LiNbO}_{3 \text { cong }}(\mathrm{Li} / \mathrm{Nb}=0.946), 2-\mathrm{LiNbO}_{3}: \mathrm{Y}$ (0.24) : $\mathrm{Mg}:\left(0.63\right.$ wt.\%), $3-\mathrm{LiNbO}_{3}: \mathrm{Gd}(0.25): \mathrm{Mg}(0.75 \mathrm{wt} . \%)$, $4-\mathrm{LiNbO}_{3}: \mathrm{Mg}$ (5.05) : Fe (0.009 mol.\%). $T=293 \mathrm{~K}[12]$.

ве), практически все структурные дефекты $\mathrm{Nb}_{\mathrm{Li}}$ будут вытеснены катионами $\mathrm{Mg}^{2+}$ и в дальнейшем с увеличением концентрации катионы $\mathrm{Mg}^{2+}$ начнут занимать основные позиции катионов $\mathrm{Li}^{+}$и $\mathrm{Nb}^{5+}$ идеальной стехиометрической структуры, формируя дефекты $\mathrm{Mg}_{\mathrm{Li}}$ и $\mathrm{Mg}_{\mathrm{Nb}}$. Одновременно с процессом образования дефектов $\mathrm{Mg}_{\mathrm{Li}}$ и $\mathrm{Mg}_{\mathrm{Nb}}$ возникают дефектные центры $\mathrm{Fe}_{\mathrm{Nb}}$, образованные на месте основных позиций $\mathrm{Nb}_{\mathrm{Nb}}$, вытесненных катионами $\mathrm{Fe}^{3+}$. Происходит формирование самокомпенсирующихся пар: $\mathrm{Mg}_{\mathrm{Li}}^{+}-\mathrm{Mg}_{\mathrm{Nb}}^{3-}, \mathrm{Mg}_{\mathrm{Li}}^{+}-\mathrm{Fe}_{\mathrm{Nb}}^{2-}$. Данные пары имеют большую силу притяжения для атома водорода, связанного с атомом кислорода водородной связью, так как обладают большим эффективным отрицательным зарядом. В результате образуется комплексный дефект $\mathrm{Mg}_{\mathrm{Li}}-\mathrm{OH}-\mathrm{M}_{\mathrm{Nb}}$, которому соответствуют полосы поглощения в ИК спектре с частотами 3526 и $3535 \mathrm{~cm}^{-1}$ (рис. 4, кривая 4), и комплексный дефект $\mathrm{Mg}_{\mathrm{Li}}-\mathrm{OH}-\mathrm{Fe}_{\mathrm{Nb}}$, которому соответствует полоса поглощения с частотой $3506 \mathrm{~cm}^{-1}$.

Наличие катионов железа $\mathrm{LiNbO}_{3}: \mathrm{Mg}(5.05)$ : : $\mathrm{Fe}(0.009 \mathrm{~mol} \%$ \%) приводит к уменьшению концентрации $\mathrm{OH}^{-}$-групп согласно данным, представленным в работе [25]. Катионы $\mathrm{Fe}$ в выращенном кристалле существуют в комплексе с $\mathrm{OH}^{-}$-группами. При увеличении концентрации катионов $\mathrm{Fe}$ в расплаве все больше ОН-ионов будет расходоваться на образование этих комплексных дефектов. То есть чем больше концентрация железа в кристалле $\mathrm{LiNbO}_{3}: \mathrm{Mg}: \mathrm{Fe}$, тем меньше концентрация других дефектных комплексов с $\mathrm{OH}^{-}$-группами в этом кристалле.

Расположение атомов водорода на длинных $\mathrm{O}-\mathrm{O}$ связях $(336 \mathrm{pm})$ приводит к существенно более высокой частоте валентных колебаний $\mathrm{OH}^{-}$-групп, чем их расположение на более коротких связях $[6,45]$. При этом, по нашему мнению, вклад в различие частот (и соответственно в значение квазиупругих постоянных связей $\mathrm{O}-\mathrm{H})$ в спектре конгруэнтного кристалла и кристалла $\mathrm{LiNbO}_{3}: \mathrm{Mg}(5.05 \mathrm{~mol} . \% \mathrm{MgO}): \mathrm{Fe}(0.009 \mathrm{~mol} . \%$ $\left.\mathrm{Fe}_{2} \mathrm{O}_{3}\right)$ может вносить также различие электроотрицательностей $\left(\mathrm{Mg}^{2+}(\sim 1.3)\right.$ и $\left.\mathrm{Fe}^{3+}(\sim 1.8)\right)$ и ионных радиусов основных и легирующих катионов. Согласно данным работы [46], полосы поглощения в ИК спектре по частоте будут близки друг другу и будут значительно перекрываться, если радиус катиона легирующей добавки близок к радиусу основных катионов $\mathrm{Li}^{+}$ и $\mathrm{Nb}^{5+}$. В противном случае полосы поглощения будут отделены друг от друга. Многозарядные катионы $\mathrm{Fe}^{3+}$ имеют больший ионный радиус $(0.67 \AA)$, чем радиусы ионов $\mathrm{Mg}^{2+}(0.65 \AA), \mathrm{Li}^{+}(0.66 \AA)$ и $\mathrm{Nb}^{5+}(0.66 \AA)$ [47]. Все это приводит к сдвигу в высокочастотную область частот валентных колебаний $\mathrm{OH}^{-}$-групп в спектре кристалла $\mathrm{LiNbO}_{3}: \mathrm{Mg}(5.05): \mathrm{Fe}(0.009 \mathrm{~mol} . \%)$ (рис. 4), что свидетельствует о большем значении квазиупругих постоянных связей $\mathrm{O}-\mathrm{H}$ и о большем „возмущении“ кислородных октаэдров О6 легированных кристаллов по сравнению с октаэдрами в конгруэнтном кристалле $\mathrm{LiNbO}_{3}$.

Характерной особенностью расположения трехвалентных редкоземельных (RE) примесей в структуре кристалла $\mathrm{LiNbO}_{3}$ является возможность занять одну из четырех катионных позиций: три октаэдрические позиции $\left(\mathrm{Li}^{+}, \mathrm{Nb}^{5+}\right.$, свободный октаэдр) и промежуточная тетраэдрическая позиция. Солегирование трехвалентной REпримесью приводит к появлению четырех видов самокомпенсирующихся пар [48]. Однако для полного понимания механизма вхождения примесей необходимо учитывать валентность, относительную электроотрицательность и ионный радиус легирующих примесей. Ионный радиус легирующей примеси RE-металлов превышает ионные радиусы катионов $\mathrm{Li}^{+}(0.66 \AA)$ и катионов $\mathrm{Mg}^{2+}$ $(0.65 \AA)$. Значение относительной электроотрицательности RE-металлов варьирует от 1.1 до 1.3 и отличается от значения относительной электроотрицательности катионов $\mathrm{Li}^{+}(0.98)$ намного больше, чем для катионов магния $\mathrm{Mg}^{2+}$ (1.31). Таким образом, представляется возможным существование самокомпенсирующихся пар $\mathrm{Mg}_{\mathrm{Li}}-\mathrm{RE}_{\mathrm{Nb}}$ и $\mathrm{Mg}_{\mathrm{Li}}-\mathrm{Mg}_{\mathrm{Nb}}$. В работах $[48,49]$ показано, что трехвалентные Re-ионы в кристалле $\mathrm{LiNbO}_{3}$ занимают в основном позиции $\mathrm{Li}^{+}$. Небольшое искажение 
кристаллической решетки за счет большого радиуса REиона приводит к тому, что RE-ионы находятся не в Liпозиции, а сдвинуты на $0.46 \AA$ вдоль направления сегнетоэлектрической оси $Z$ [48-50]. В экспериментальных и теоретических исследованиях $[51,52]$ считается, что REионы в структуре кристалла $\mathrm{LiNbO}_{3}$ занимают основные позиции $\mathrm{Nb}^{5+}$, что согласуется с данными работ [53,54] о расположении RE-ионов в кристаллах $\mathrm{LiNbO}_{3}: \mathrm{Mg}: \mathrm{RE}$. В исследованиях $[33,45]$ высказано предположение, что в конгруэнтных кристаллах $\mathrm{LiNbO}_{3}: \mathrm{Mg}: \mathrm{RE}$ и $\mathrm{LiNbO}_{3}: \mathrm{RE}$ дополнительные полосы поглощения в ИК спектрах в области валентных колебаний водородных связей связаны с образованием новых комплексных дефектов. Данные дефектные комплексы формируются в таких кристаллах при достижении некоторой пороговой концентрации RE-примеси. Для RE-примесей пороговая концентрация подразумевает расположение RE-ионов в $\mathrm{Nb}$-позиции кристаллической решетки $\mathrm{LiNbO}_{3}$.

Согласно данным работы [4], в кристаллах $\mathrm{LiNbO}_{3}: \mathrm{Y}: \mathrm{Mg}$ значительная часть трехвалентных ионов занимает случайные позиции в кристаллической решетке $\mathrm{LiNbO}_{3}$ и даже частично не замещают точечные дефекты $\mathrm{Nb}_{\mathrm{Li}}, V_{\mathrm{Li}}$, а также катионы ниобия, расположенные в основных позициях идеальной структуры кристалла. Так как концентрация магния в этом кристалле достигает значения второй пороговой концентрации ( 5.5 мол.\% $\mathrm{MgO}$ в расплаве), в структуре кристалла $\mathrm{LiNbO}_{3}: \mathrm{Y}: \mathrm{Mg}$ происходит формирование комплексного дефекта $\mathrm{Mg}_{\mathrm{Li}}^{+}-\mathrm{Mg}_{\mathrm{Nb}}^{3-}-\mathrm{OH}^{-}$, которому соответствует полоса поглощения с частотой $3535 \mathrm{~cm}^{-1}$ (рис. 4, кривая 4). Легирующие трехвалентные катионы $\mathrm{Y}^{3+}$ в комплексном дефекте $\mathrm{Mg}-\mathrm{OH}-\mathrm{Y}^{3+}$ могут замещать либо позиции $\mathrm{Li}$, либо позиции $\mathrm{Nb}$ [55]. В ИК спектре при этом будут отсутствовать полосы поглощения, соответствующие новым комплексным дефектам, обусловленным наличием $\mathrm{OH}^{-}$-групп в кристалле. Аналогичное поведение проявляется у избыточных катионов

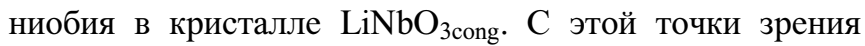
можно объяснить сходство спектров ИК поглощения кристалла $\mathrm{LiNbO}_{3 \text { cong }}$ и кристалла двойного легирования $\mathrm{LiNbO}_{3}: \mathrm{Y}(0.24): \mathrm{Mg}:(0.63$ wt.\%) (рис. 4, кривые 1 и 2).

Смещение ИК спектра кристалла $\mathrm{LiNbO}_{3}: \mathrm{Gd}(0.25)$ : $: \operatorname{Mg}\left(0.75\right.$ wt.\%) на $\sim 50 \mathrm{~cm}^{-1}$ в высокочастотную область (рис. 4, кривая 3) связано с большим ионным радиусом (111 pm) и большим атомным весом (157) легирующей примеси $\mathrm{Gd}$ по сравнению с данными показателями для других элементов $\mathrm{Nb}$ (66 pm и 92), $\mathrm{Li}(66$ pm и 7), Y (106 pm и 89). Вхождение легирующих катионов $\mathrm{Gd}^{3+}$ в структуру кристаллической решетки изменяет кислородный октаэдр, приводит к увеличению кислородной связи. Это в свою очередь повышает частоту валентных колебаний ОН-групп и объясняет сдвиг спектра кристалла $\mathrm{LiNbO}_{3}: \mathrm{Gd}(0.25): \mathrm{Mg}(0.75$ wt.\%) в длинноволновую область.

\section{Заключение}

Таким образом, присутствие атомов водорода в структуре кристалла $\mathrm{LiNbO}_{3}$ приводит к образованию с основными $\left(\mathrm{Nb}^{5+}\right.$ и $\left.\mathrm{Li}^{+}\right)$, легирующими катионами $(\mathrm{Me})$ и вакансиями $(V)$ комплексных дефектов: $V_{\mathrm{Li}}-\mathrm{OH}$, $\mathrm{Nb}_{\mathrm{Li}}-\mathrm{OH}, \mathrm{Me}-\mathrm{OH}, \mathrm{Me}-\mathrm{OH}-\mathrm{Me}$ и др. Наличие в структуре монокристалла ниобата лития разных позиций атомов водорода, связанных с атомом кислорода водородными связями, приводит к изменению количества и параметров полос поглощения ИК спектра в области валентных колебаний водородных связей. Для реального высокоупорядоченного стехиометрического кристалла $(\mathrm{Li} / \mathrm{Nb}=1)$ высокой степени структурного совершенства в ИК спектре наблюдалась единственная узкая полоса поглощения с частотой $3466 \mathrm{~cm}^{-1}$, ширина которой равна $3 \mathrm{~cm}^{-1}$. Этот факт свидетельствует о единственной позиции атомов водорода в структуре кристалла $\mathrm{LiNbO}_{3}$. При любом отклонении от стехиометрии $(\mathrm{Li} / \mathrm{Nb} \neq 1)$ в спектре наблюдаются несколько (не более шести) более широких полос поглощения, свидетельствующих о нескольких позициях атомов водорода в структуре кристалла. Таким образом, изменение количества позиций атомов водорода в структуре монокристалла $\mathrm{LiNbO}_{3}$ позволяет с достаточной точностью судить о соответствии его состава стехиометрическому составу $(\mathrm{Li} / \mathrm{Nb}=1)$. Этот факт позволил установить, что по технологии HTTSSG из конгруэнтного расплава с добавлением флюса $\sim 6.0$ wt.\% $\mathrm{K}_{2} \mathrm{O}$ на ростовых установках Кристалл-2 можно получать близкие по составу к стехиометрическим ( $\mathrm{Li} / \mathrm{Nb} \sim 1)$ кристаллы $\mathrm{LiNbO}_{3 \text { stoich }}$ (6.0 wt.\% $\left.\mathrm{K}_{2} \mathrm{O}\right)$ приблизительно с такой же дефектностью подрешетки атомов водорода, как и в стехиометрических кристаллах $\mathrm{LiNbO}_{3 \text { stoich, }}$ выращенных из расплава, содержащего $\sim 58.6 \mathrm{~mol} \% \mathrm{Li}_{2} \mathrm{O}$, но значительно превосходящие кристаллы $\mathrm{LiNbO}_{3 \text { stoich }}$ по общей оптической и структурной однородности $[31,32]$.

Изменения в спектре ИК поглощения в области частот валентных колебаний $\mathrm{OH}^{-}$-групп кристаллов $\mathrm{LiNbO}_{3}: \mathrm{Me}(\mathrm{Me}=\mathrm{Zn}, \mathrm{Mg}, \mathrm{Y}, \mathrm{Gd})$ обусловлены образованием комплексных дефектов различного вида: $\mathrm{Me}_{\mathrm{Li}}-\mathrm{OH}^{-}, \mathrm{Me}_{\mathrm{Li}}-\mathrm{Me}_{\mathrm{Nb}}-\mathrm{OH}$. Точечные дефекты $\mathrm{Me}_{\mathrm{Li}}$ и $\mathrm{Me}_{\mathrm{Nb}}$ в позициях катионов $\mathrm{Li}$ и $\mathrm{Nb}$ идеальной стехиометрической структуры формируют самокомпенсирующуюся пару $\mathrm{Me}_{\mathrm{Li}}-\mathrm{Me}_{\mathrm{Nb}}$, которая имеет большую силу притяжения для атомов водорода, связанных с атомами кислорода водородной связью, что и приводит к формированию комплексного дефекта $\mathrm{Me}_{\mathrm{Li}}-\mathrm{Me}_{\mathrm{Nb}}-\mathrm{OH}$. Полученные данные свидетельствуют об изменении при прохождении концентрационных порогов характера комплексообразования ОН-групп с точечными дефектами катионной подрешетки. ИК спектры поглощения в области частот валентных колебаний водородных связей серии кристаллов $\mathrm{LiNbO}_{3}: \mathrm{Mg}$ и $\mathrm{LiNbO}_{3}: \mathrm{Zn}$ при концентрациях легирующей примеси до первого концентрационного порога схожи с ИК спектром номинально чистого кристалла конгруэнтного состава. С прибли- 
жением концентрации легирующей примеси ко второму концентрационному порогу ( 5.5 mol.\% $\mathrm{MgO}$ и $\sim 7 \mathrm{~mol} . \% \mathrm{ZnO}$ ) происходит постепенное вытеснение дефектов $\mathrm{Nb}_{\mathrm{Li}}$ катионами $\mathrm{Mg}$ и $\mathrm{Zn}$. В дальнейшем катионы $\mathrm{Mg}$ и $\mathrm{Zn}$ начинают занимать позиции катионов $\mathrm{Li}$ и $\mathrm{Nb}$ идеальной стехиометрической структуры, формируя комплексные дефекты $\mathrm{Mg}(\mathrm{Zn})_{\mathrm{Li}}-\mathrm{OH}$ и $\mathrm{Mg}(\mathrm{Zn})_{\mathrm{Nb}}-\mathrm{OH}$, которым соответствуют полосы поглощения с частотами 3526 и $3535 \mathrm{~cm}^{-1}$.

Анализ механизмов образования комплексных дефектов в кристалле двойного легирования $\mathrm{LiNbO}_{3}: \mathrm{Mg}(5.05): \mathrm{Fe}(0.009 \mathrm{~mol} \%$ ) показал появление комплексных дефектов $\left(\mathrm{Fe}_{\mathrm{Nb}}\right)-\mathrm{OH}-\left(\mathrm{Mg}_{\mathrm{Li}}\right)$, $\left(\mathrm{Mg}_{\mathrm{Li}}\right)-\left(\mathrm{Mg}_{\mathrm{Nb}}\right)-\mathrm{OH}$. При этом коэффициент вхождения катионов $\mathrm{Fe}$ уменьшается вследствие присутствия в кристалле катионов Mg. В то же время даже незначительное содержание катионов $\mathrm{Fe}$ в кристалле вызывает изменение параметров элементарной ячейки кристалла $\mathrm{LiNbO}_{3}: \mathrm{Mg}: \mathrm{Fe}$ и поляризуемости кислородных октаэдров, что приводит к изменению оптических свойств кристалла.

\section{Конфликт интересов}

Авторы заявляют, что у них нет конфликта интересов.

\section{Список литературы}

[1] Ю.С. Кузьминов. Электрооптический и нелинейнооптический кристалл ниобата лития (Наука, Москва, 1987).

[2] Н.В. Сидоров, Т.Р. Волк, Б.Н. Маврин, В.Т.Калинников. Ниобат лития: дефекты, фоторефракиия, колебательный спектр, поляритоны (Наука, Москва, 2003).

[3] K. Lengyel, A. Peter, L. Kovacs, G. Corradi, L. Palfavi, J. Hebling, M. Unferdorben, G. Dravecz, I. Hajdara, Zs. Szaller, K. Polgar. Appl. Phys. Rev., 2, 040601 (2015). DOI: $10.1063 / 1.4929917$

[4] L. Kovacs, M. Wöhlecke, A. Jovanovic, K. Polgar, S. Kapphan. J. Phys. Chem. Sol., 52 (6), 797 (1991). DOI: 10.1016/0022-3697(91)90078-E

[5] L. Kovacs, Zs. Szaller, K. Lengyel, G. Corradi. Opt. Mat., 37, 55 (2014). DOI: 10.1016/j.optmat.2014.04.043

[6] J.M. Cabrera, J. Olivares, M. Carrascosa, J. Rams, R. Müller, E. Diéguez. Adv. Phys., 45 (5), 349 (1996). DOI: $10.1080 / 00018739600101517$

[7] L. Arizmendi, E.J. Ambite, J.L. Plaza. Opt. Mat., 35 (12), 2411 (2013). DOI: 10.1016/j.optmat.2013.06.043

[8] Z. Galazka. J. Cryst. Growth., 178 (3), 345 (1997). DOI: $10.1016 / \mathrm{S} 0022-0248(96) 01159-1$

[9] K. Lengyel, L. Kovacs, A. Peter, K. Polgar, G. Corradi, A. Baraldi, R. Capelletti. Appl. Phys. Lett., 96, 191907 (2010). DOI: $10.1063 / 1.3428772$

[10] T. Volk, M. Wohlecke. Lithium niobate. Defects, photorefraction and ferroelectric switching (Springer, Berlin, 2008).

[11] Y. Kong, W. Zhang, X. Chen, J. Xu, G. Zhang. J. Phys: Cond. Mat., 11 (9), 2139 (1999). DOI: 10.1088/0953-8984/11/9/010

[12] Y. Kong, J. Xu, W. Zhang, G. Zhang. J. Phys. Chem. Sol., 61 (8), 1331 (2000). DOI: 10.1016/S0022-3697(99)00413-8
[13] С.В. Евдокимов, А.В. Яценко. Кристаллогр., 48 (4), 594 (2003). [S.V. Yevdokimov, A.V. Yatsenko. Cryst. Rep., 48 (4), 542 (2003). DOI: 10.1134/1.1595175]

[14] А.Н. Лазарев, Я.И. Рыскин, Г.П. Ставицкая. Колебания окисных решеток (Наука, Ленинград, 1980).

[15] M. Engelsberg, R.E. de Souza, L.H. Pacobahyba, G.C. do Nascimento. Appl. Phys. Lett., 67, 359 (1995). DOI: $10.1063 / 1.114628$

[16] А.В. Яценко. Укр. физ. журн., 44 (3), 411 (1999).

[17] S.C. Abrahams, P. March. Acta Crystallogr., Sect. B: Struct. Sci., 42 (2), 61 (1986). DOI: 10.1107/S0108768186098567

[18] S.C. Abrahams. Properties of Lithium Niobate (Pergamon, New York, 1989).

[19] S.C. Abrahams, J.M. Reddy, J.L. Bernstein. J. Phys. Chem. Sol., 27 (6/7), 997 (1966). DOI: 10.1016/0022-3697(66)90072-2

[20] Y. Watanabe, T. Sota, K. Suzuki, N. Iyi, S. Kimura. J. Physics: Condens. Matter., 7 (18), 3627 (1995). DOI: $10.1088 / 0953-8984 / 7 / 18 / 025$

[21] Y. Furukawa, K. Kitamura, S. Tadekawa, K. Niwa, Y. Yajima, N. Iyi, I. Mnushkina, P. Guggenheim, J.M. Martin. J. Cryst. Growth., 211 (1-4), 230 (2000). DOI: $10.1016 / \mathrm{S} 0022-0248(99) 00794-0$

[22] K. Lengyel, V. Timon, A. Hernandez-Laguna, V. Szalay, L. Kovacs. IOP Conf. Ser.: Mater. Sci. Eng., 15, 012015 (2010). DOI: $10.1088 / 1757-899 X / 15 / 1 / 012015$

[23] H.H. Nahm, C.H. Park. Appl. Phys. Lett., 78(24), 3812 (2001). DOI: $10.1063 / 1.1376667$

[24] J.R. Herrington, B. Dischler, A. Räuber, J. Schneider. Sol. Stat. Commun., $12(5), 351$ (1973). DOI: 10.1016/00381098(73)90771-0

[25] M. Cochez, M. Ferriol, P. Bourson, M. Aillerie. Opt. Mater., 21 (4), 775 (2003). DOI: 10.1016/S0925-3467(02)00098-8

[26] K. Lengyel, L. Kovacs, A. Peter, K. Polgar, G. Corradi. Appl. Phys. B: Lasers and Optics., 87 (2), 317 (2007). DOI: $10.1007 / \mathrm{s} 00340-007-2589-7$

[27] L. Kovacs, I. Foldvari, I. Cravero, K. Polgar, R. Capelletti. Phys. Lett. A., 133(7-8), 433 (1988). DOI: 10.1016/03759601(88)90931-0

[28] A. Gröne, S. Kapphan. J. Phys. Chem. Sol., 56 (5), 687 (1995). DOI: 10.1016/0022-3697(94)00184-7

[29] R. Bhatt, S. Kar, K.S. Bartwal, V. Shula, P. Sen, P.K. Sen, V.K. Wadhawan. Ferroelectrics, 323 (1), 165 (2005). DOI: $10.1080 / 00150190500309148$

[30] K. Polgar, A. Peter, L. Kovacs, G. Corradi, Zs. Szaller. J. Cryst. Growth., 177 (3-4), 211 (1997). DOI: 10.1016/S00220248(96)01098-6

[31] Н.В. Сидоров, М.Н. Палатников, Л.А. Бобрева, С.А. Климин. Неорг. матер., 55 (4), 395 (2019).

DOI: $\quad 10.1134 / S 0002337 X 19040134 \quad$ [N.V. Sidorov, M.N. Palatnikov, L.A. Bobreva, S.A. Klimin. Inorg. Mater., 55 (4), 365 (2019). DOI: 10.1134/S0020168519040137]

[32] Н.В. Сидоров, М.Н. Палатников, Л.А. Бобрева. ЖСХ, 60 (9), 1434 (2019). DOI: 10.26902/JSC_id46180

[N.V. Sidorov, M.N. Palatnikov, L.A. Bobreva. J. Structural Chemistry, 60, 1434 (2019). DOI: 10.26902/JSC_id46180]

[33] X.Q. Feng, J.F. Ying, Y.A. Wu, J.C. Liu. Chin. Sci. Bull., 36, 297 (1991).

[34] A. Reisman, F. Holtzberg. J. Amer. Chem. Soc., 80, 6503 (1958). DOI: $10.1021 / \mathrm{ja} 01557 \mathrm{a} 010$

[35] Н.В. Сидоров, П.Г. Чуфырев, М.Н. Палатников, В.Т. Калинников. Нано- и микросистемная техника, (3), 12 (2006). 
[36] J.J. Liu, W.L. Zhang, G.Y. Zhang. Phys. St. Sol. A., 156 (2), 285 (1996). DOI: 10.1002/pssa.2211560207

[37] М.Н. Палатников, Н.В. Сидоров, О.В. Макарова, И.В. Бирюкова. Фундаментальные аспекты технологии сильно легированных кристаллов ниобата лития (Изд-во КНЦ РАН, Апатиты, 2017).

[38] M.N. Palatnikov, N.V. Sidorov, D.V. Manukovskaya, O.V. Makarova, L.A. Aleshina, A.V. Kadetova. J. American Ceramic Society, 100 (8), 3703 (2017).

DOI: $10.1111 /$ jace.14851

[39] N. Iyi, K. Kitamura, F. Izumi, J.K. Yamamoto, T. Hayashi, H. Asano, S. Kimura. J. Sol. State Chem., 101, 340 (1992). DOI: $10.1016 / 0022-4596(92) 90189-3$

[40] B.C. Grabmaier, F. Otto. J. Cryst. Growth., 79(1-3), 682 (1986). DOI: 10.1016/0022-0248(86)90537-3

[41] T. Zhang, B. Wang, F.R. Ling, S.-Q. Fang, Y.-H. Xu. Mater. Chem. Phys., 83 (2-3), 350 (2004). DOI: $10.1016 /$ j.matchemphys.2003.10.010

[42] H. Wang, J. Wen, B. Li, H. Wang. Phys. St. Sol. (a), 118 (1), K47 (1990). DOI: 10.1002/pssa.2211180151

[43] X.H. Zhen, L.C. Zhao, Y.H. Xu. Appl. Phys. B., 76 (6), 655 (2003). DOI: 10.1007/s00340-003-1158-y

[44] Y. Fan, C. Xu, S. Xia, C. Guan, L. Cao, Q. He, G. Jin. J. Cryst. Growth., 312, 1875 (2010).

DOI: 10.1016/j.jcrysgro.2010.03.001

[45] L. Kovács, L. Rebouta, J.C. Soares, M.F. da Silva, M. HageAli, J.P. Stoquert, P. Siffert, J.A. Sanz-Garcia, G. Corradi, Z. Szaller, K. Polgar. J. Phys-Condens. Matt., 5, 781 (1993).

[46] Y. Kong, J. Deng, W. Zhang, J. Wen, G. Zhang, H. Wang. Phys. Lett. A., 196 (1-2), 128 (1994). DOI: 10.1016/03759601(94)91057-X

[47] И.Т. Гороновский, Ю.П. Назаренко, Е.Ф. Некряч. Краткий справочник по химии. 5-е изд., под ред. А.Т. Пилипенко (Наук. думка, Киев, 1987).

[48] L. Rebouta, P.J.M. Smulders, D.O. Boerma, F. Aguillo, Lopez, M.F. da Silva, J.C. Soares. Phys. Rev. B., 48, 3600 (1993). DOI: 10.1103/PhysRevB.48.3600

[49] A. Lorenzo, H. Jaffrezic, B. Roux, G. Boulon, J. Garcia-Sole. Appl. Phys. Lett., 67 (25), 3735 (1995).

DOI: $10.1063 / 1.115366$

[50] T. Gog, M. Griebenow, G. Materlik. Phys. Lett. A., 181 (5), 417 (1993). DOI: 10.1016/0375-9601(93)90398-J

[51] G. Burns, D.F. O’kane, R.S. Title. Phys. Rev., 167 (2), 314 (1968). DOI: 10.1103/PhysRev.167.314

[52] T. Tsuboi, S.M. Kaczmarek, G. Boulon. J. Alloys Compd., 380 (1-2), 196 (2004). DOI: 10.1016/j.jallcom.2004.03.043

[53] H.-N. Dong, S.-Y. Wu, W.-C. Zheng. J. Phys. Chem. Sol., 64 (4), 695 (2003). DOI: 10.1016/S0022-3697(02)00381-5

[54] S.H. Choh, J.H. Kim, I.-W. Park, H.J. Kim, D. Choi, S.S. Kim. Appl. Magn. Reson., 24, 313 (2003). DOI: $10.1007 / \mathrm{BF} 03166932$

[55] L. Kovacs, L. Kocsor, Z. Szaller, I. Hajdara, G. Dravecz, K. Lengyel, G. Corradi. Crystals, 7(8), 230 (2017). DOI: $0.3390 /$ cryst7080230 